\title{
توسعة أحواض مرمى الجمرات ورأي الفقهاء فيه
}

\author{
كميَّة بحث وجمع الباحثة \\ منال بنت خرصان بن يعلا \\ محاضرة في قسم الفقه كلية الشريعة في جامعة نجران

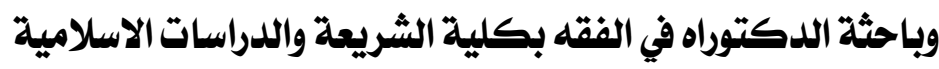 \\ بجامعة أم القرى - المملكة العربية السعودية
}




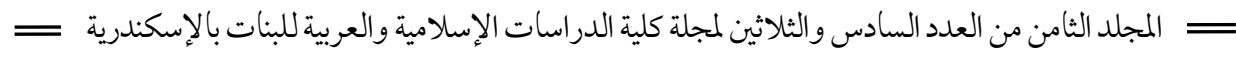
توسعة أحو اض مرمئ الجمرات ورأي الفتهاء فيه 


\section{توسعة أحواض مرمى الجمرات ورأي الفقهاء فيه}

منال نت خرصان بن يعلا قسم الفقه - كلية الشريعة - جامعة بجران - المملكة العربية السعودية Manal1199@yahoo.com : البريد الاليكتروني

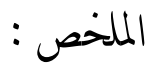

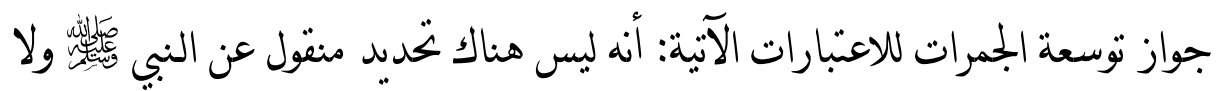
عن أصحابه في تحديد مساحة الجمـرات، أن هناك حاجـة ماسـة لتوسعة الجمرات لضيق دائرة المرمى، ولما يحصل فيها من الزحام الشديد، والحاجة تنزل منزلة الضرورة ،

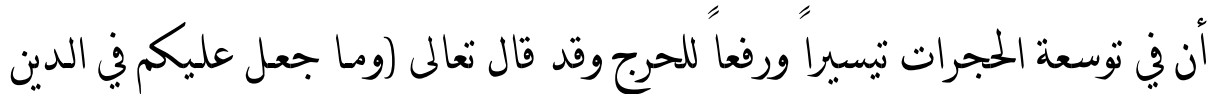
من حرج) فلو بقيت سعة الجمرات على وضعها الحالي لحصل للناس ضيق وحرج

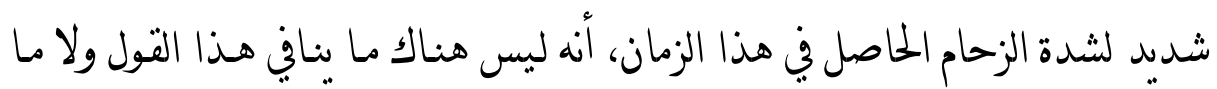
يدل على بطلانه فلا نبنغي المصير إلى ما فيه تشديد وتضيبيق على الناس وترك ما فيه.

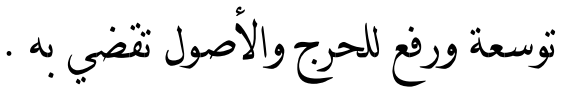

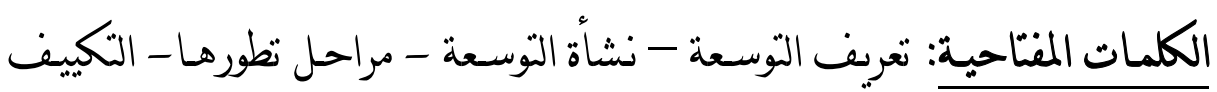

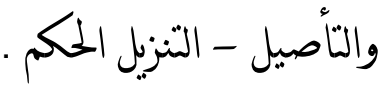




\section{The expansion of the Jamarat range basins and} the opinion of the jurists in it

Manal bint Khurasan bin Yaala Jurisprudence Department - College of Sharia Najran University - Kingdom of Saudi Arabia E-mail : Manal1199@yahoo.com

Summary :

nor from his companions in determining the area of the Jamarat, that there is an urgent need to expand the Jamarat due to the narrow circle of the goal, and because of the severe crowding that takes place in it, the need descends to the status of necessity, that in expanding the rooms, the easiness and the lift To be embarrassed, and the Almighty said: (And what has been made upon you in religion $\mathrm{It}$ is permissible to expand the Jamarat for the following considerations: that there is no determination conveyed from the Prophet If the capacity of the Jamarat remained in its current position, people would be distressed and embarrassed by the intensity of the crowding that is occurring at this time, that there is nothing to contradict this statement or to indicate its invalidity, so there is no need for the fate of what includes stress 


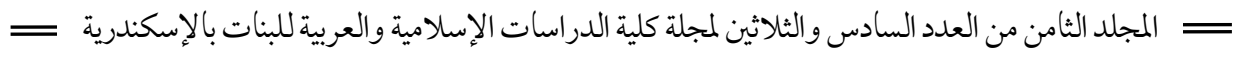

and constraint on people and leaving what is in it expansion and lifting of embarrassment The assets dictate it.

Keywords: definition of expansion - the emergence of expansion - stages of its development - adaptation and rooting download judgment.

$r \cdot 1=$ 


\section{管}

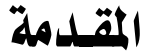

الحمد لله على إحسانه وامتنانه، والصلاة والسلام على سيد الاولبن والاخرين، المبعوث رحمه للعالمن وعلى من أقتقى أثره وصار على نهجه إلى يوم الدين . أما بعد ........ أن من نعم الله على عباده أن نوع لهم طرق عبادته، فبعضها عبادات مالية، وبعضها عبادات بدنية، ومنها ما يجمع الأمرين، والجج أحد هذه العبادات التي بتمع بين التعبد بالمال والتعبد بالبدن، وفيه تتجلى مظاهر الوحدانية لله رب العالمبن بطرائق مختلفة، كما تتجلى فيه عظمة هذه الملة، ملة الإسـلام، وارتباطها التاريخي العقدي بالملل السابقة، فلا غرو أن يجعل الله فعله من أعظم القربات التي ينال بها أعظم الحسنات، فعن أبي

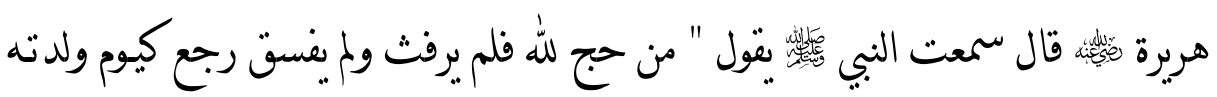

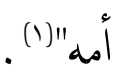

ولقد كان القيامُ بمنسك, الحج بعيدا عن نعقيدات العصر الحديث ، من كثرة عدد ، ومشتاق تنقلٍ ولأن الله سبحانه وتعالى جعل البيت الحرام مثابة للناس وأمناً ، وجعل ".

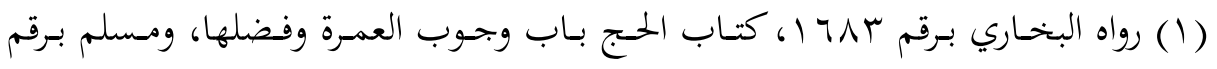
9 \& 1 1، كتاب الحج، باب فضل الحج والعمرة ويوم عرفة.

$=r \cdot r=$ 
الصلاة فيه تعادل مئة الف صلاة في غيره من المساجد ، وجعل أفندة الناس تهوي إليه،

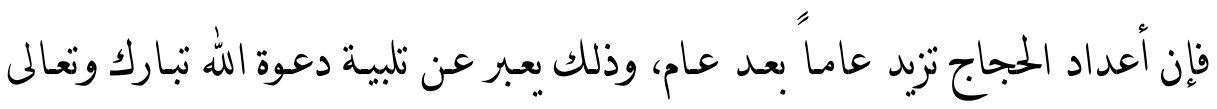
لأداء فريضة الحتج ، وإتمام الدين ، ويزبد الازدحام في مناطق المشاعر، خاصة عند منطقة رمي الجمرات بوداي منى، والتي تنعلقُ بها النازلة التي شحن بصدد تناولها، والتي تقع عند نهابة وادي منى من ناحية الشمال الغربي •

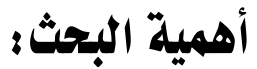

مع ازدياد المسلمبن، وازدياد إقبـالهم على نعـاليم دنهم يزّداد عدد حجاج بيـت الله الحرام، الأمر الذي بيجعل أداء بعض مناسك هذا الركن العظبم بعترِه شيء من الصعوبة وربما المشقة، وذلك أن أداء هذه المناسك لابد أن شّم في مكان واحد في وقت واحد وتتضح أهمية الموضوع زيادة على ما سبق إيراده بما ليلي:

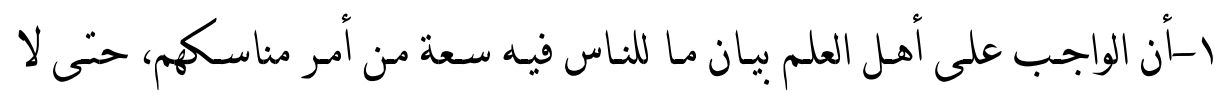
بصيبهم حرج ومشقة أثناء أداء هذا الركن العظيم على وجهه الخصوص، أو أداء غيره من الشعائر على وجه العموم. 
ـأن على أهل العلم أن ينبهوا الناس على ما ليس فيه سعة بل هـو أمر حتم لا مفر من فعله، وليس هذا مما ينافي سر الشربعة ورفعها الحرج عن الأمة.

ـأن مسألة رمي الجمرات من المسائل التي حعل بسببها مشقة عظيمة لا تخفى على أحد ، فكان الاشتغال ببحث فروعها من الاشتغال بما يهم المسلمبن.

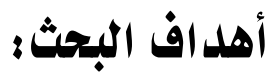

ا-بيان الحكم الشرعي لتوسعة الاحواض من خلال تصورها وتكييفها ثم تنزيل الحكم

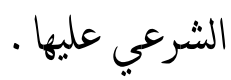
r-إثبات استمرار أحكام الشريعة ومواكبهنا للحوادث والنوازل المستجدة.

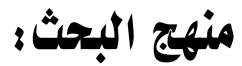

البحث قائم على الاعتماد على المنهج الاستقرائي' التحليلي 'النقدي المقارنْ وذلك من خلال ذكر أقوال الفقهاء وأدلهم وما بطراً عليها من مناقشات وأجوبة. والمقارن وهو ذكر أقوال العلماء المعاصرين والتزجيح مع بيان سببه.

المنهج الاستقرائي : وهو: المنهج القائم على تتبع الفروع والجزئيات من أجل الوصول إلى الى الميات

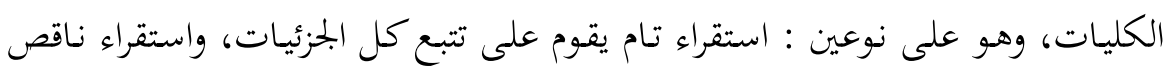

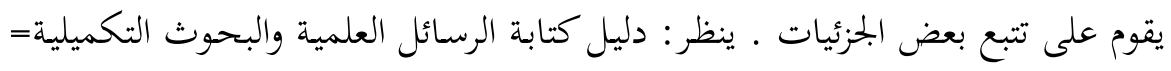




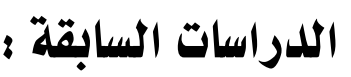

لقد بجثت مسائل رمي الجمرات بعامة، ومنها مسألة محل البحث هذه كمسألة من خلال نوعبن من الدراسات. ا - فقد بجثت كمسألة من مسائل الحج والذي تناولت مسائه المصنفات الفقهية المعروفة سواء كانت مصنفات مختصة بمذهب من المذاهب الفقهية ، أو مصنفات عامة تُوازن المذاهب الفقهية أو مصنفات نتمّد أسلوب فقه الحدثث فقد ذكرت المسألة محل بجث كثير من المصنفات الفقهية الشاملة فلا داعي

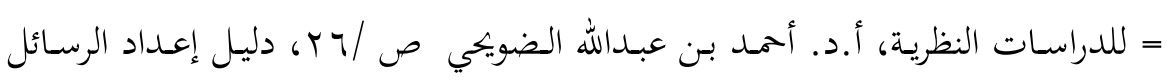

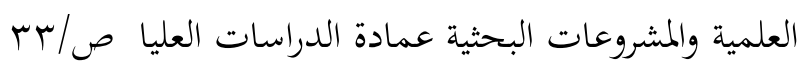

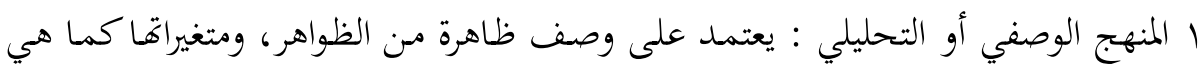

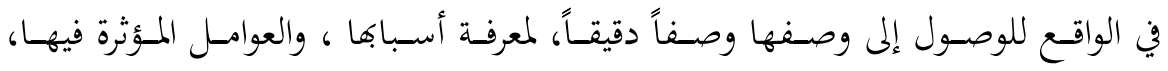

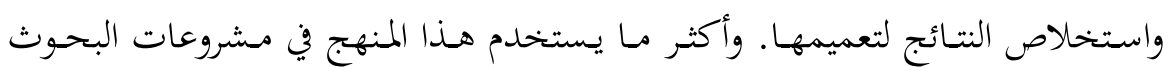

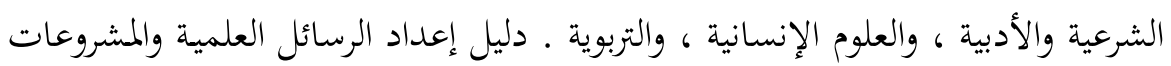

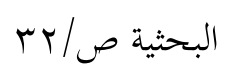

ب المنهج المقارن : وهو الذي يتمبهُ فيه توضيح الوحدات، أو الصفات الميشتركة، أو المختلفة

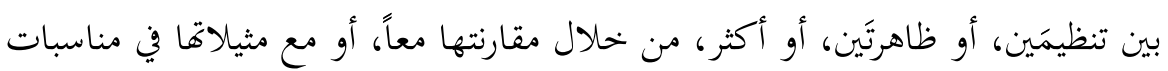

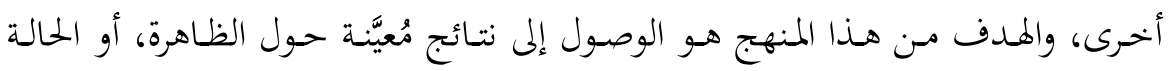

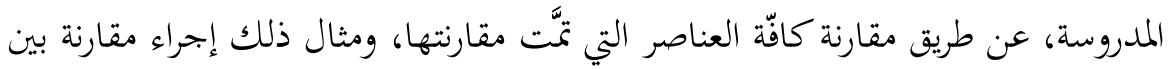

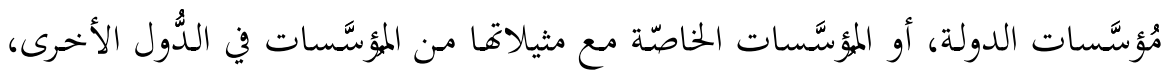

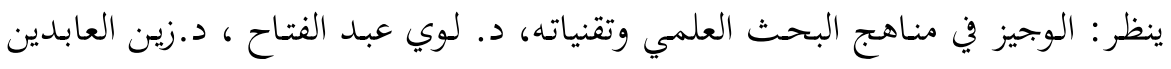

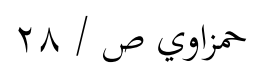


لإطالة البحث بذكر هذه المصنفات الفقهية والتي سيُرد بعضها في حواشي البحث في

ثبت المراجع، ولكن بعض هذه الدراسات كانت مستّلة بهذا الموضوع ومنها ( رمي الجمرات وما نتعلق بهه من أحكام دراسـة مقارنة في الفقه الاسـلامي ) من إعداد د. شرف بن علي الشريف ، وقد طبع في جامعة أم القرى بمكة المكرمة عام · اع اهـ .

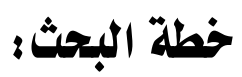

المقدمة وتشمل على أهمية البحث وأهدافه ومنهجه والدراسات السابقة والخطة . المبحث الأول: تصوير نازلة توسعة مرمى الاحواض، بذكر تعربها ونشأنها، ومراحل

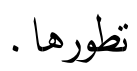
المبحث الثاني: التكيف والتأصيل الفقهي لتوسعة أحواض الجمرات. المبحث الثالث: التنزيل الحكم على النازلة مع إبراد الادلة في اختّف العلماء في التوسعة ومناقشات والأجوبة عليها وبيان الراجح في المسألة مع ذكر السبب. 


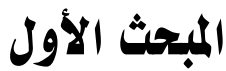

\section{تصوير توسعة أحواض مرمى الجمرات}

التوسعة مِ اللغة: مصدر وسع الشيء أي جعله واسعاً وهي ضد الضيق ووسع الله عليه في الرزق أغناه، والتوسعة في الرزق أو النفقة والبسط بمعنى واحد (1) .

الأحو اض مِّ اللفة: هو جمتمع الماء، والجمع أحواض . وحياض . وحوض الرسول . ولا يخزج المعنى اللغوي عن المعنى الاصطلاحي. رمي الجمرات : لفة، واصطلاحاً:

$$
\text { الرمي لغة: هو القذف والدفع. }
$$

وهو في الاصطلاح: دفع الحصى الصغار بِقُوَةٍ إلى موضع الرمي داخل حوض

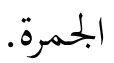

الجمرات، لغة: الجمرة: الحصاة الصغيرة، وجمعها جمرات، وبمار ((')).

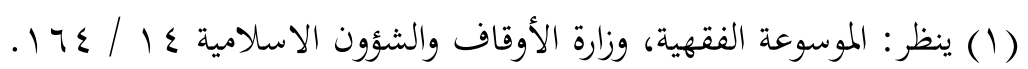

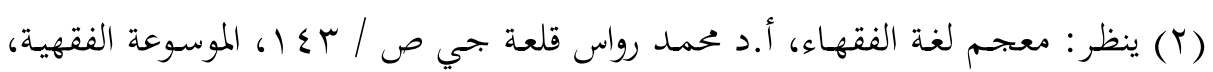
. $r \leqslant V / 1 \Lambda$

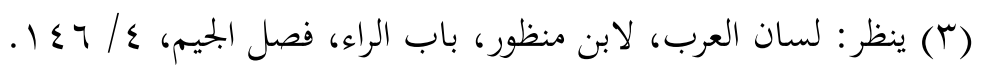


قـال الإمـام ابـن الأتير رحمه الله: ((...الجمـار : وهي الأحجـار الصغار، ومنـه سميّيت جمار الحج للحصى التي يُرَىى بها، وأما موضع الجمار بمنىق فسُمِّيَ جمرة؛ لأهما تُرمى بالجمار، وقيل: لأكها بحمع الحصى التي يُرمى بها، من الجمـرة: وهي اجتماع القبيلة على من نَاوَأها، وقيل: سُمِيّت به من قولهم: أجمر : إذا أسرع((1).

وقال العلامة أحمد الفيُّومي رحه الله: ((الجمرة هي بحتمع الحصى بمنى، فكلهُ كومةٍ

$$
\text { من الحصى جمرة، والجمع: جمرات، وجمرات منى ثلاث ..()( ). }
$$

وعلى هذا فاشتقاق الجمرة: من التجمّر : وهو التجمّع؛ لاجتماع الحصى في

$$
\text { الموضع الذي يُرمى فيه. }
$$

أو سميّيت الجمرة من التجمّع لاجتماع الحجاج عندها يرموها، والعلم عند الله تعالى ((r)).

الجمرة لِّ الاصطلاح: هي بحتمع الحصى الذي تحت العمود الشاخص

$$
\begin{aligned}
& \text { (1) ينظر: النهاية في غريب الحديث والأثر لابن الأثير، مادة (جمر)، // ب ج ب. }
\end{aligned}
$$

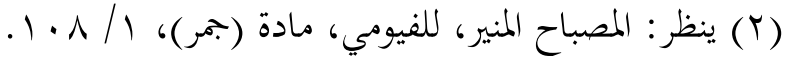

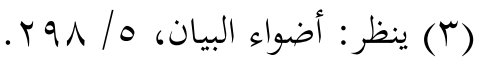


الذي يقع وسط الحوض في الجمرة الصغرى والجمرة الوسطى ويقع الحوض في جهة جمرة العقبة الغربية الجنوبية ()) فإذا وقع الحصى داخل الحوض تحت العمود

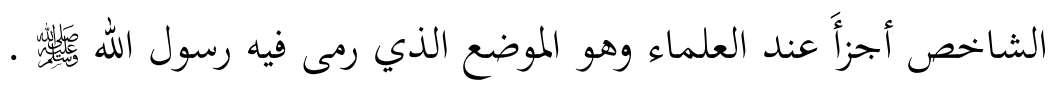

\section{النشأة التاريخية لتوسعة أحواض الجمرات:}

لقد مرت الجمرات عبر التاريخ منذ عهد إبراهيم الخليل عليه السلام إلى عهد الجاهلية، تم عهد رسول الله والخلفـاء الراشدين وحتى يومنـا هـذا، بمراحل عـدة، وكانت أحسواض الجمرات لا تتعدى منطقة صغيرة محددة بارتفاع صغير من تراب ونحوه.

ولم تكـن الشواخص الحاليـة معروفـة إلا مـن عهــ قريـب، إذ بـدت الحاجـة ملحـة لهـا بازدياد أعداد الحجاج، وربما كانت بداية نشأقا في العهد العثماني. أما الأحواض التي حول الأعمدة، فإها أحدثت بعد سنة بو ب اهـ، لتخفيف الزحام وجمع الحصى في مكان واحد (1) في القـرن الـثالث عـشر الهجـري بــأت تظهـر التطـورات، بــأت بوضـع شـباك حديدي حول الجمرات. (1) 
وبعد ذلك أزيل الشباك، وبنيت أحواض حول الجمار الثلاث عام rو ب اهـ. ولقد شهدت المنطقة عدداً من مراحل التطوير، لتخفيف المعاناة عن الحجاج وتمكينهم من أداء نسكهم في يسر وسهولة، فكانت التوسـعة الأولى في العصـر العباسي، وتمثلت في توسعة الطريق وتبليطه، وكان أول ظهور للشاخص مكان الجمرات في العصر الأيوبي بناء على ما وصفه الرحالة ابن جبير، وشبه علم جمرة العقبة بأعلام الحرم المكي. إذ ذكر أن جمرة العقبة تقع على قارعة الطريق مرتفعة نتيجة تراكم حصى الجمار، ويعلو الجمرة مسجد مبارك وبنيت الأحواض في العهد العثماني. أما الجمرات في العهد السعودي في عامبا؟ اهـ فقد شهدت هذه المرحلة زيادة في أعداد المسلمين، وقد ترافق معها زيادة أعداد من يقصدون البيت الحرام من الحجاج، فنتج زحام غير قليل في موسم الحج، فعمدت الحكومات السعودية إلى التخفيف منه عبر تنفيذ عدد من المشاريع على مراحل عدة.  وجعل من ورائها من الجهة الشمالية الشرقية قاعدة بناء حتى يمنع من يريد الرمي خلفها. 
ب r ا هـ: هدم المنطقة ما بين الجمرة الوسطى وجمرة العقبة لتصل المسافة بين

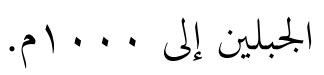

ه9 ا هـ: توسعة المنطقة المحيطة بالجمرات وبناء جسر على الجمرات الثلاث، وزيد ارتفاع علم الجمرات ليراه الرامي من أعلى الجمسر، فيما أبقي حوض الجمرات السفلي على حالته مستديرا، ونصف مستدير حول جمرة العقبة. ه. • اهـ: بناء جسر الجمرات بعرض ·ع مترا، ولزيادة أعداد الحجاج وسع في

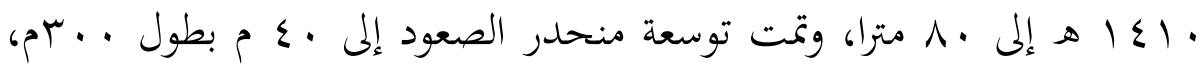
ومنحدر الذهاب إلى الحرم بطول . . ب م. 0 ا 1 هـ: توسعة أحواض الجمرات، فتحولت من الشكل الدائري إلى البيضاوي مع المحافظة على أن تقع الجمار في مكان الرمي المعهود.واستمرت الجهود في توسعة أحواض الجمرات حتى أصبح أحد أهم المشاريع الحديثة التي نفذتها وزارة الشؤون البلدية والقروية في المشاعر المقدسة، وذلك نظراً لأن المشروع بما تضمنه من خطط تطوير استطاع أن يحقق هدفا مهما واستراتيجيا وهو تمكين أكبر قدر من الحجاج من تأدية هذا النسك دون حوادث تؤثر على سلامتهم

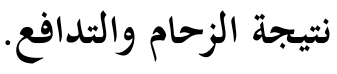


ويعد مشروع تطوير رمي الجمرات ثمرة جهود الدولة بقيادة خادم الحرمين الشريفين لمواكبة أعداد الحجاج وتأمين راحتهم وسلامتهم أثناء تأديتهم

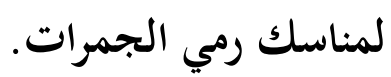
وقد استمرت فترة دراسات مشروع تطوير رمي الجمرات أكثر من أربع سنوات انتهت بالموافقة على المشروع وترسيته والمباشرة بتنفيذه في نهاية ربيع الآخر من عام ج ب ا ا هـ حيث بلغت مدة التنفيذ أربع سنوات وثمانية أشهر انتهت بموسم حج • بـ اهـ، ليصل المشروع إلى وضعه الجديد الحالي لاستيعاب أكبر عدد من الحجاج ويحقق الأهداف المرجوة من إنشائها في الحفاظ على أرواح الحجاج وتمكينهم من أداء هذا النسك في سهولة ويسر. وكان من أهداف إنشاء هذا المشروع توفير الطاقة الاستيعابية بالمنشأة الجديدة لكي يتمكن أربعة إلى خمسة ملايين حاج على الأقل من رمي الجمرات ضمن ظروف آمنة ومريحة تحقق لهم السلامة والراحة خلال أدائهم هذا النسك، وخفض كثافة الحجاج عند مداخل الجسر وذلك بتعدد المداخل وتباعدها؛ مما يسهم في تفتيت الكتل البشرية عند المداخل 
وتسهيل وصول الحجاج إلى الجمرات من الجهة التي قدموا منها، وأيضا توسعة أحواض الرمي وتعديل شكل الأحواض؛ بما يؤمّن انسيابية الحركة حول أحواض الرمي، وتوفير الخدمات الملائمة على الجسر بإنشاء أبراج تتمركز بها كافة الجهات المعنية مباشرة لخدمة وسلامة وأمن الحجاج مع تأمين سبل الإخلاء والنظافة وكافة مستلزمات التشغيل، وتوسعة الساحات المحيطة بجسر الجمرات من كافة الجهات خاصة الشمالية والجنوبية وعند الجمرة الكبرى بما يحقق سهولة التحرك على المنسوب الأرضي ويستوعب الجسر الجديد وملحقاته، وعمل محطات لإنزال وإركاب الحجاج وذلك غرب الجمرات بعيداً عن المشعر والساحة مع توفير السبل لسهولة انتقالهم إلى الجسر، بجانب تنظيم الساحة بعد توسعتها مع إعادة تخطيط الجزء الشرقي منها بما يوفر تساوي توزيع الحجاج واستقامة الشوارع باتجاه الجسر. 


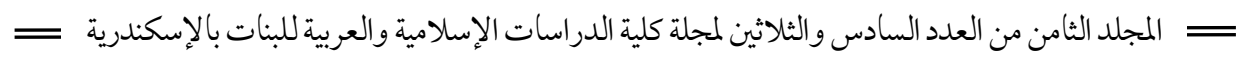
توسعة أحواض مرمئ الجمرات ورأي الفتهاء فيه

وهذه بعض الصور التوضيحية لشكل الاحواض وكيف توسعت .

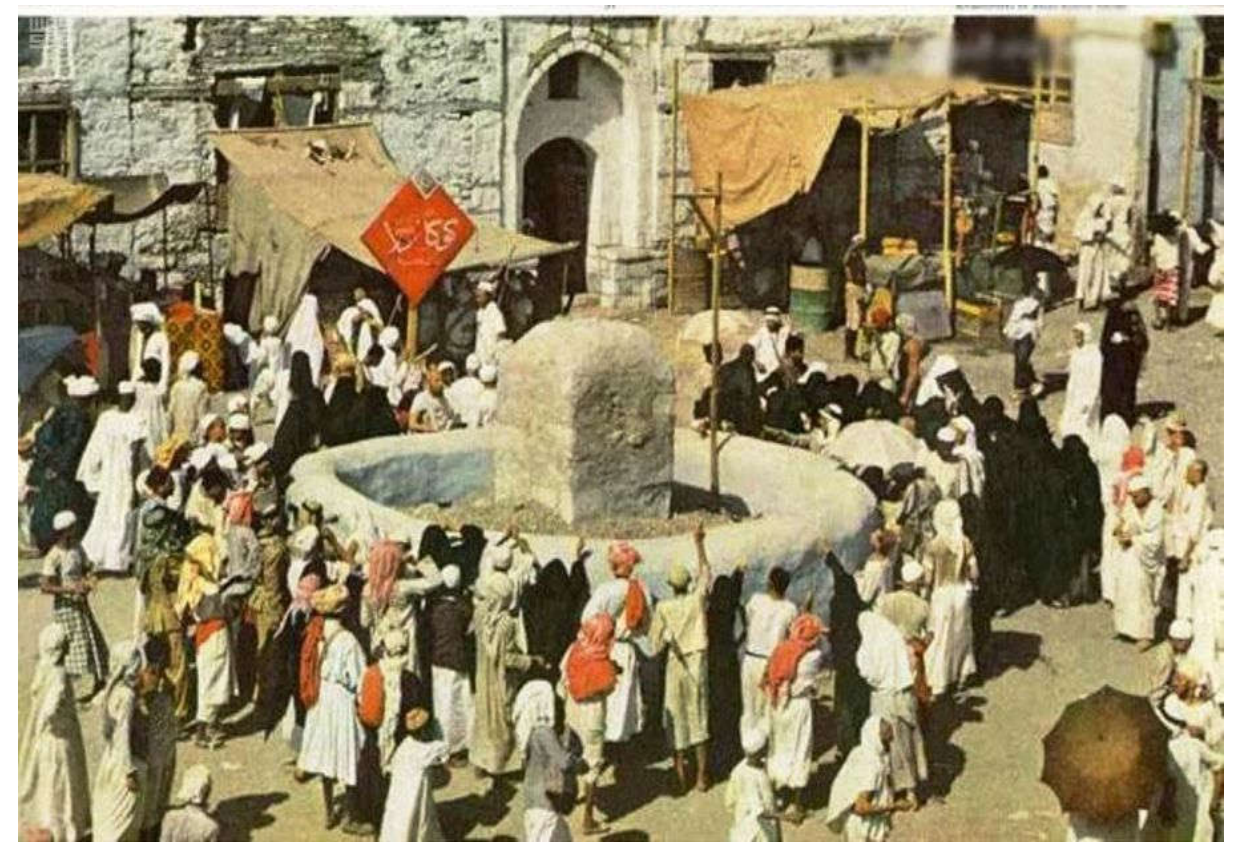




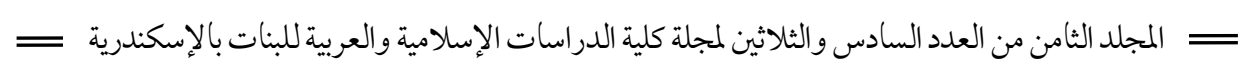

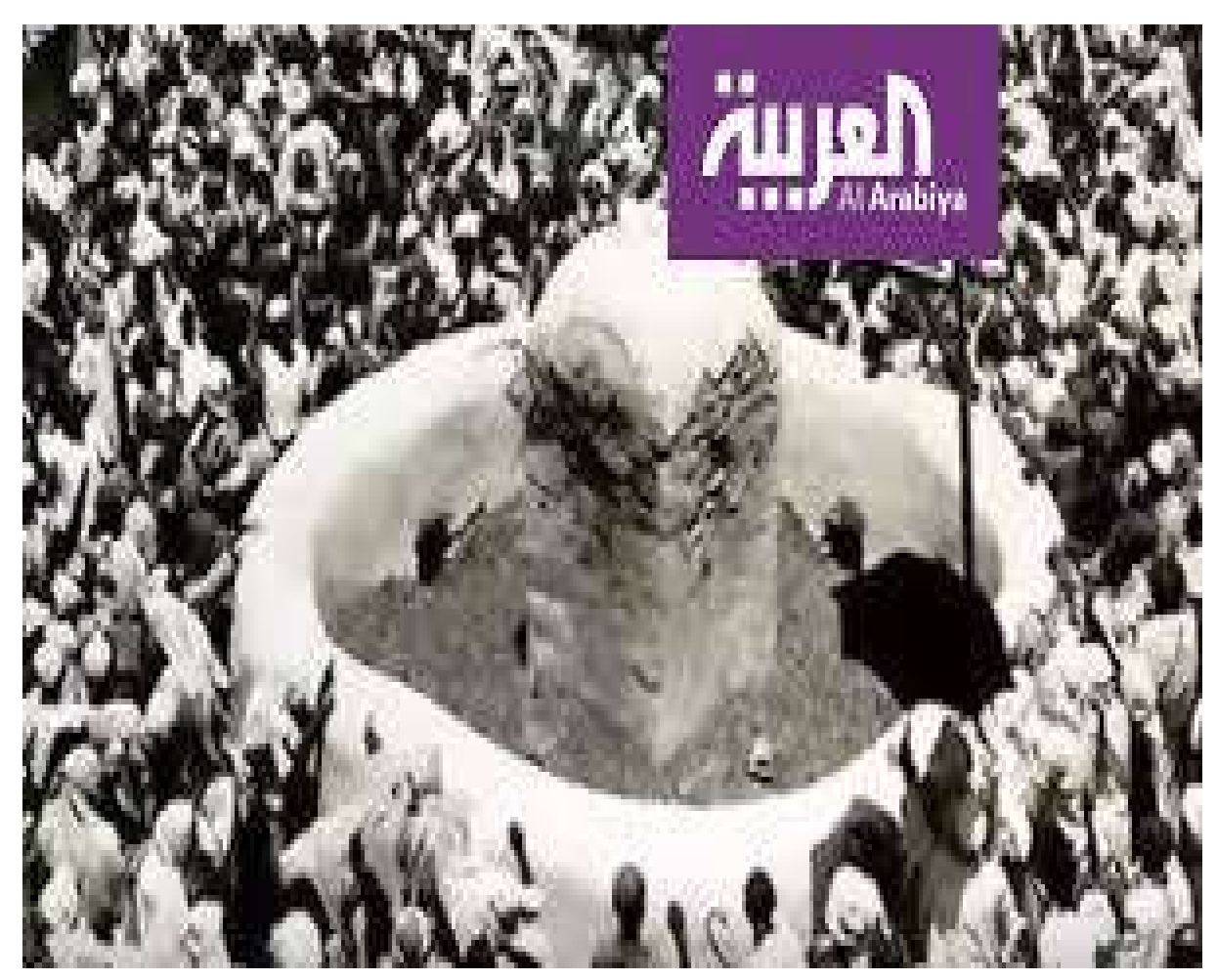




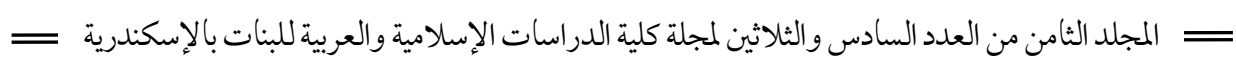
توسعة أحواض مرمئ الجمرات ورأي الفقهاء فيه

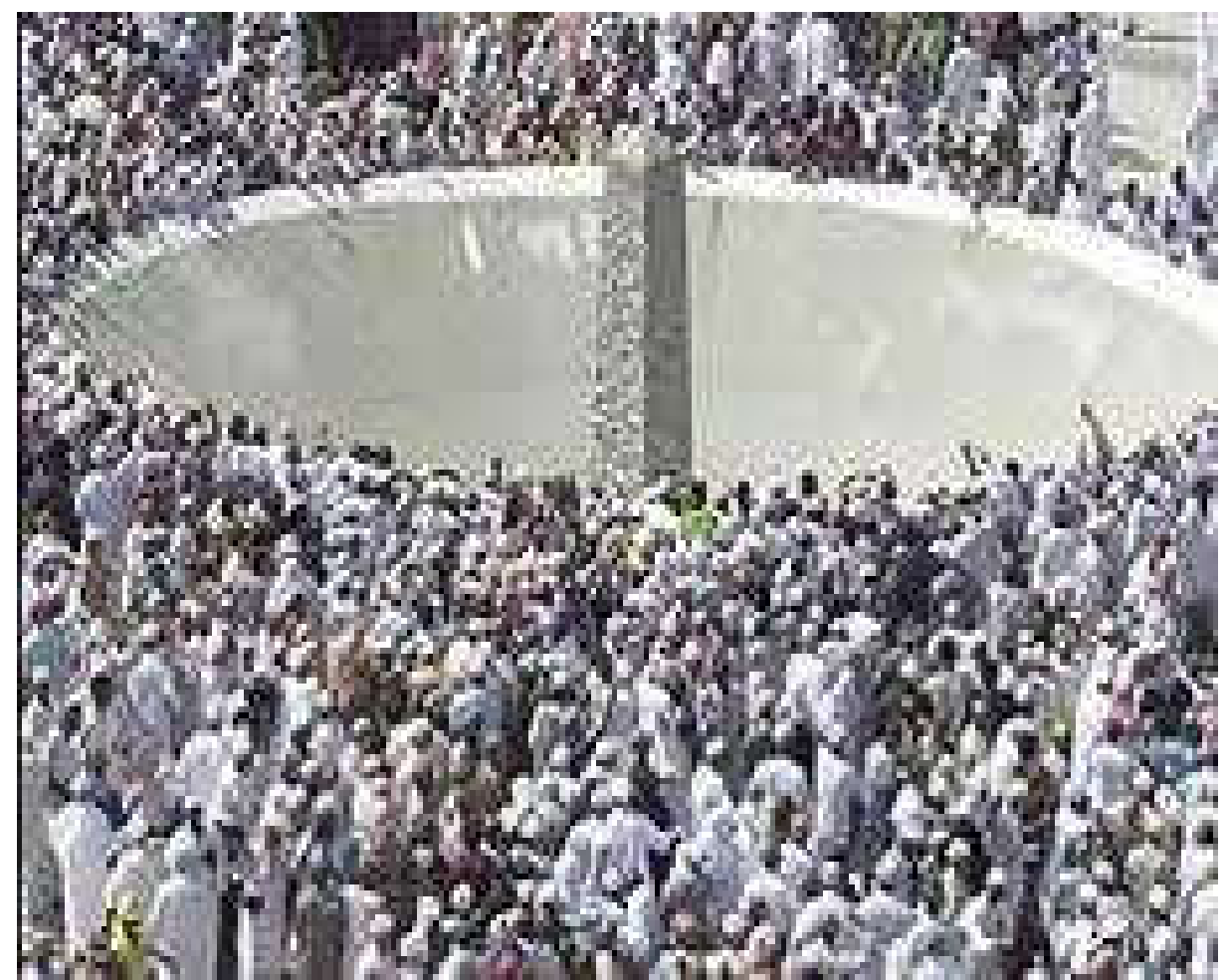




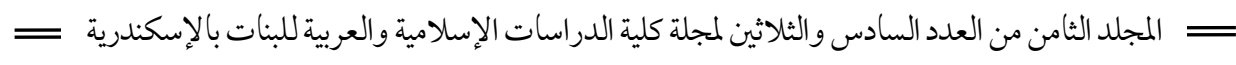

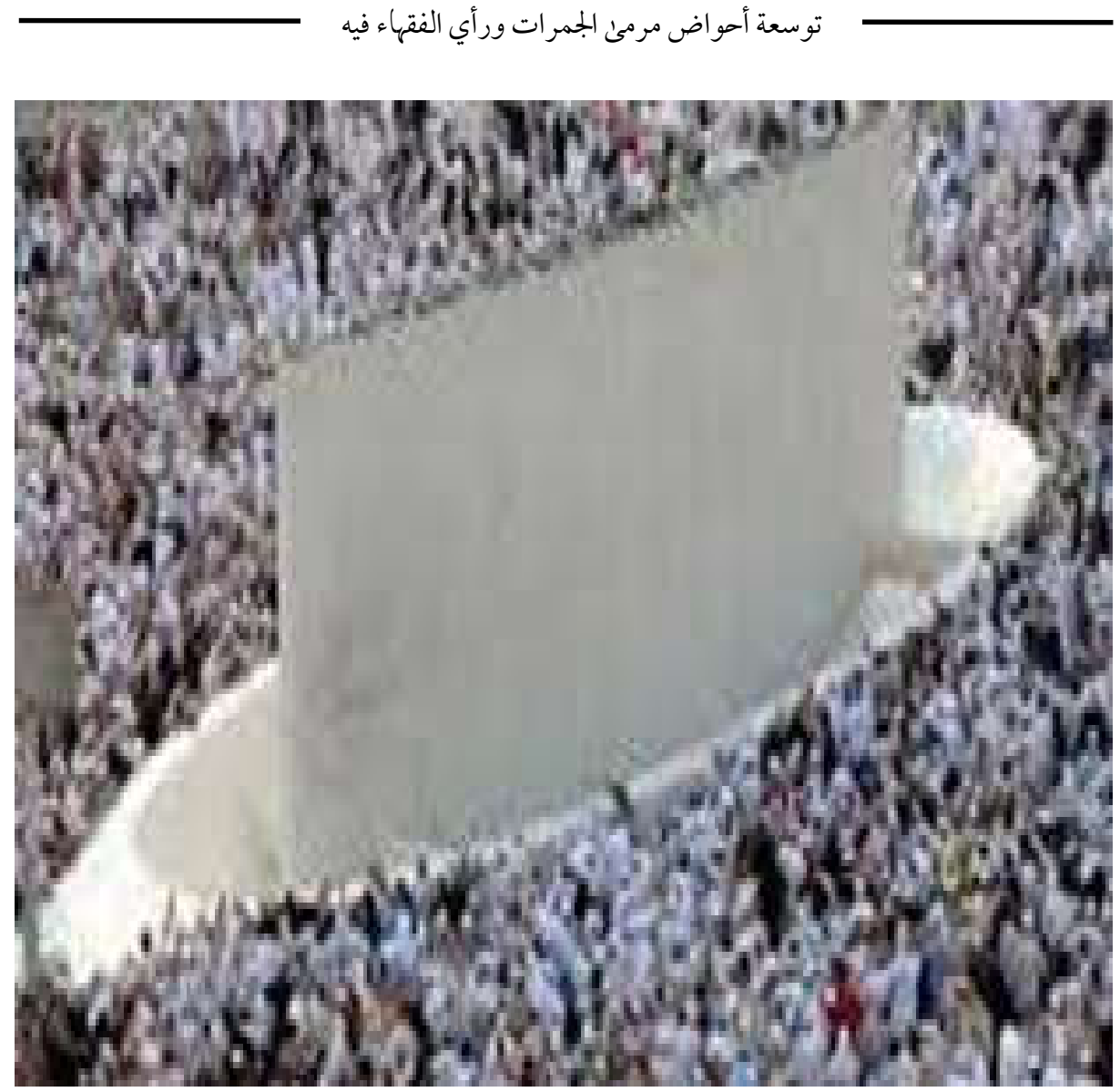




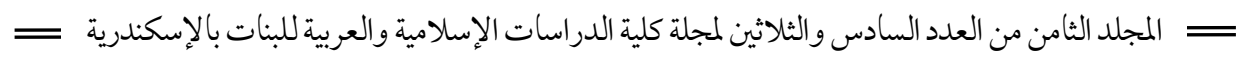

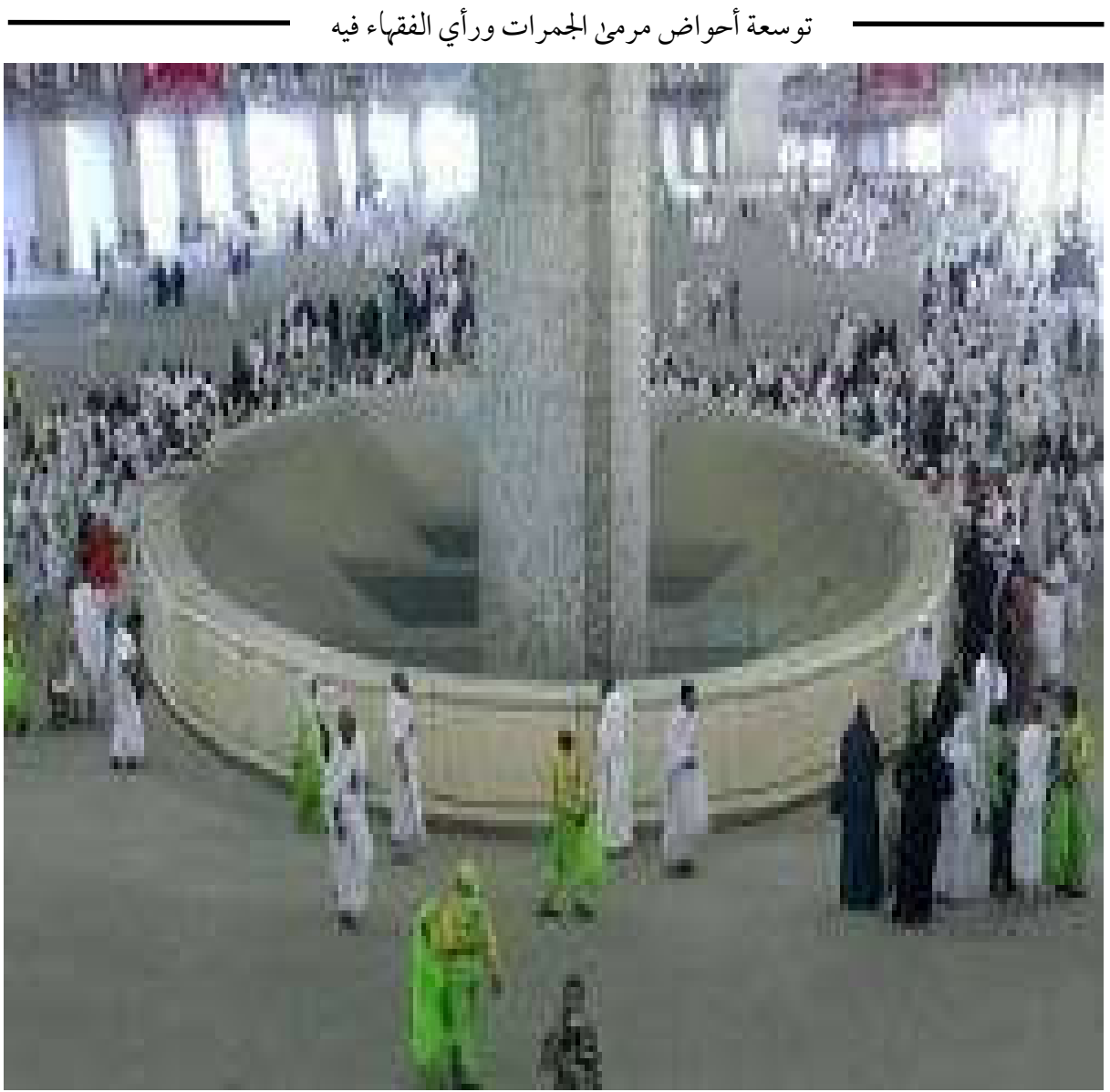




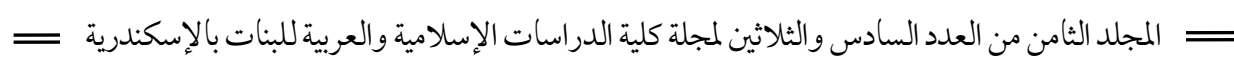

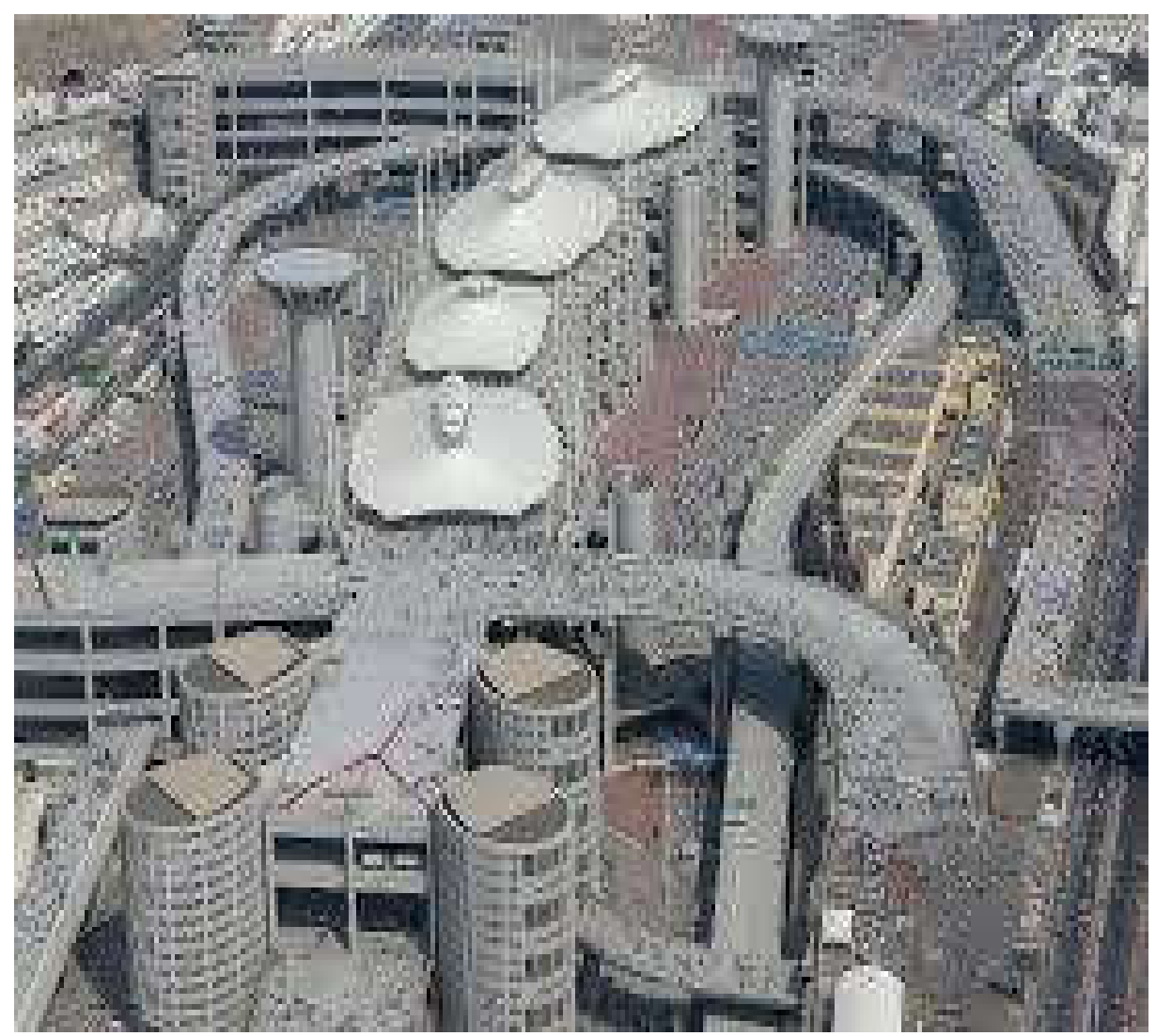




\section{لذلك أن الناظر في كتب الفقهاء يرى أن حال هرهى}

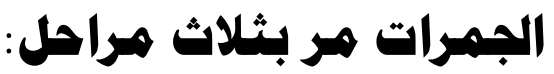

اـ المرحلة الأولي: متقدمو فقهاء المذاهب لم يذكروا حداً محدودا لسعة مرمى

الجمرات، وعامتهم اتثقوا على أنه يرمي إلى مجتمع الحصى أو ما قرب منه. أما ما بُعد

عنه فإنه لايجزئ الرمي إليه؛ وهذا بلا شك يفيد بأن الاحواض المحيطة بمرمى الجمرات

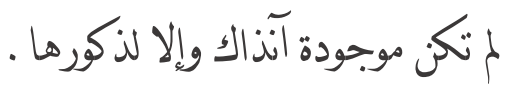

كـ المرحلة الثانية: مرحلة تقدير القرب والبعد من مرمى الجمرات، وهذا وجد

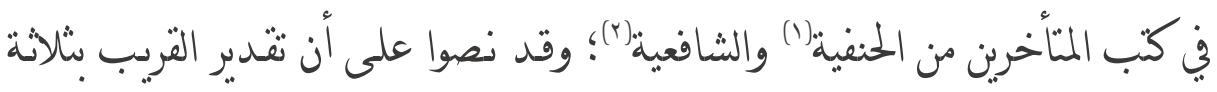

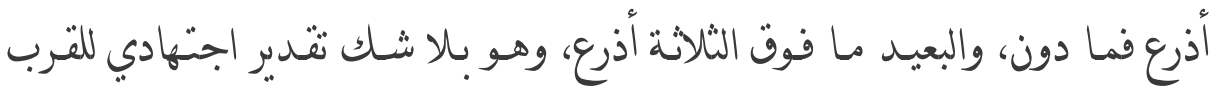
والبعد . بينما المالكية والحنالةلة لمنصوا على تحديد معبن فيما كان من مراجعهم، وإنما نصوا على أنه بجمع الخصى وما قرب منه (r).

(1) ينظر: حاشية ابن عابدين والدر المختار / / T ؟ 0.

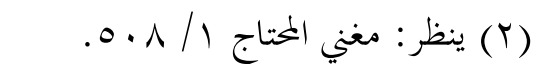

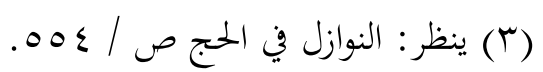


وإن كان المالكية قد نصوا في مسائل أخرى غير هذه المسألة على أن تقدير القرب والبعد من الشيء يرجع إلى العرف، بينما اعتبر الحنابلة الثلاثة أذرع فما دون مسافة قرببة من السترة للمصلي وما فوقها يعتبر بعيداً.

المرحاسة الثالثـة: وهي مرحلة وضع البنـاء الخيط بالجمرات بشكله المعروف سابقاً على شكل دائرة نصف قطرها ما ثقارب ثلاثة أذرع؛ وهذا مبني على الاجتهاد السابق في تحديد القريب والبعيد من بجمع الخصى، حيث وضع ابتداء شباك حديدي حوالي الجمـرة لإزالة الزحام باتفاق علماء الوقت في ذي القعدة الوباهـ، ولميوضع لتحديد المرمى ، واستخكره بعض العلماء ؛ ظظرا لسعته ؛ خوفاً من أن يظن بعض العوام أن جميع ما أحاط بذلك مرمى وليس كذلك ، ثم بعد ذلك في عام بوَ اهـ أزيل ذلك الشباك الواسع ، وأحسدث بدله بناء وأحواض حسل الجمار الثلاث وإن كانت بنيت بشكل واسع ثم اختصصرت إلى هـا الشكل ؛ بنـاءُ على ما قال به جملة من علماء. الحنفية والشافعية بالتحديد بثلاث أذرع ، وقد بكون وضعها بشكل واسع لمنع الزحام ، وقد بكون لقوّى بعض أهل العلم في ذلك الوقت ، ثم استمر الحال على ما تم بناؤهي ذلك العام ، حتى جاءت هذه العصور التي شهدت ققزة حضارية وتنوعاً وسرعة في وسائل المواصلات ؛ مما أناح وصول تلك الأعداد الضخمة إلى هذه المشاعر المقدسة 


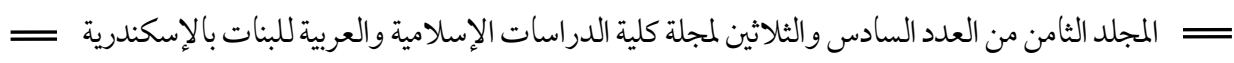

توسعة أحو اض مرمئ الجمرات ورأي الفتهاء فيه

، وتّج عنه وصول تلك الأعداد إلى الجمرات في أوقات متّاربة ، وبرعة فائتة ، فلم

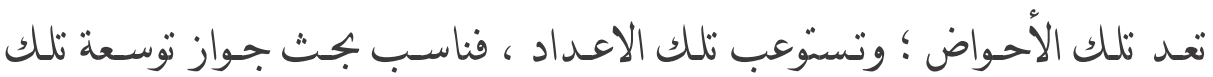
الاحـواض ؛ وقـد بجـث العلمـاء المعاصـرين من هيُّة كبـار العلمـاء بالمملكة العربيـة السعودية هذه المسالة ، وقرروا عدم جواز بناء حوض خحارجي أوسع من الحالي ، والله أعلم.

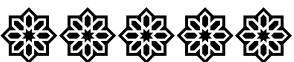




\section{المبـث الثاني}

\section{التكييف للنازلة توسعة أحواض الجمرات}

\section{اختلف الفقهاء المعاصرون في هكم تواسـعة هرهـى البمهرات}

\section{على قولين:}

الأول: ــرى عـدم جـواز توسـعنها؛ بنـاء على أن الأصـل في العبـادات والمناسـك ومشاعرها التوقيف، إذ لا بجال للعقل فيها، فلا يجوز إدخال أي تغيير عليها بالزيادة أو النقص، أو نغير حدودها أو نقل أماكنها .

وقد استقرت الأمة على حدود معينة لمرمى الجمرات فلا يجوز الزيادة عليه ، وهو رأي هيئة كبار العلماء بالمملكة العربية السعودية(Y)

الاتبـاه الثــاني: ذهب بعض البـاحثين المعاصـرين إلى جهواز توسعة أحساض

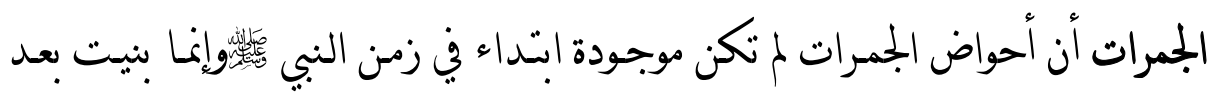

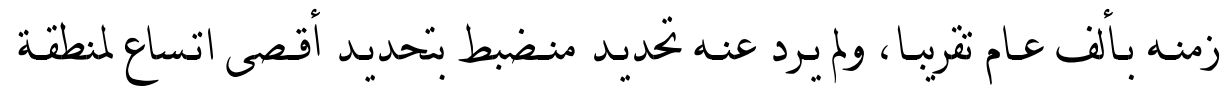
المرمى. وتحديد بعض العلماء له بثلائة أذرع إنما هو محض اجتهاد، ولما كان الأمر غير

$$
\begin{aligned}
& \text { (1) الموسوعة الميسرة في فقه القضايا المعاصرة، ص/4 آ ـ 7. }
\end{aligned}
$$

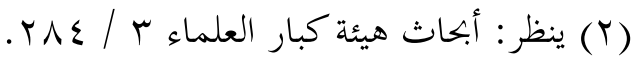




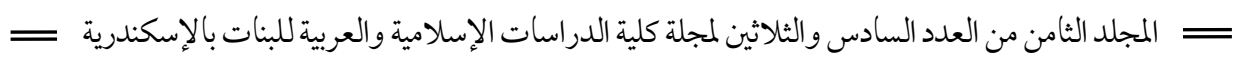

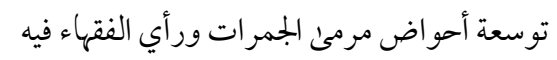

محدد بأدلة قطعية واقتضت الضرورة التوسعة جاز ذلك انظلاقا من قاعدة (الضرورات تبيح الخظظورات) وقاعدة (إذا ضاق الأمر انسع) واعمالا لمقصد من مقاصد الشريعة في رفع الحرج عن الناس.

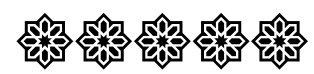




\section{المبحث الثالث}

\section{(1) التنريل الفقهي}

\section{استدل القائلون بعدم جهاز توسعة أحواض الجمرات بأدلة هي:}

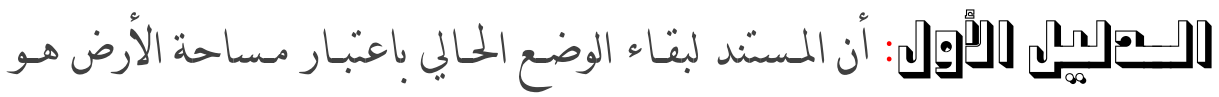
استصحاب الهكس أو الاستصحاب المقلوب(r)؛ وحتيقته ثبوت أمر في الزمن الماضي

$$
\text { (1) النوازل في الحج ص / (1) }
$$

(T) تعريف الاستصحاب في اللغة " قيل استصحبت الحال إذا تمسكت بما كان ثان ثابتاً، كأنك

$$
\text { جعلت تلك الحال مصاحبة غير مفارقة. }
$$

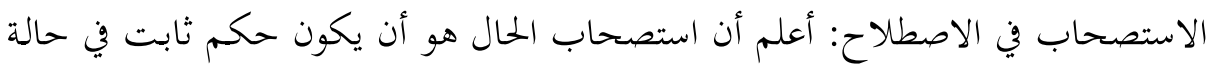

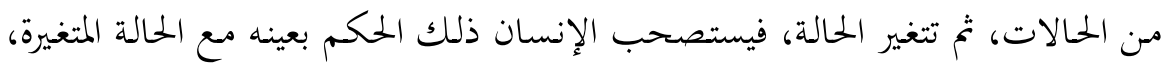
ويقول: من ادعى تغير الحكم، فعليه إقامة الدليل. ومعناه عند الأكثرين: "الحكم بثبوت أمر في الزمان الثاني بناءً على أنه كان ثابتاً في الزمان النمان الأول" ومناه عند الأو

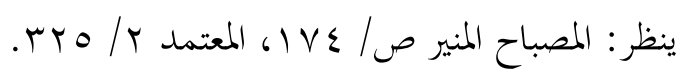

تعريف الاستصحاب المقلوب في اللغة: الشيء المحول من جهة إلى أخرى معاكسة لها، أي: الماني

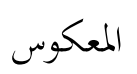

تعريفه في الاصطلاح: الاستدلال بالعادة الموجودة الآن على وجودها في الزمن الماضي.

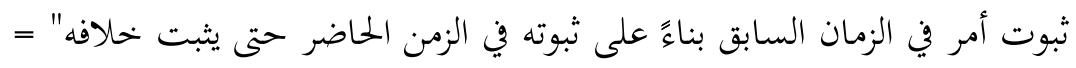


بناء على ثبوته في الزمن الحاضر؛ وهو حجة على الراجح، لأن هذه المواضع متحددة. الآن، والأصل أنه لم بطرأ عليها تغير، فتبت لها ذلك في الزمن الماضي بناء على ثبوته

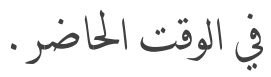

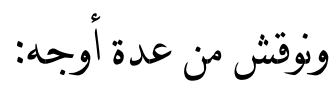

لا نسلم بـأن الاستصحاب المقلوب حجـة معتبرة؛ ولم يقل بـه إلا الشافعية في مسألة

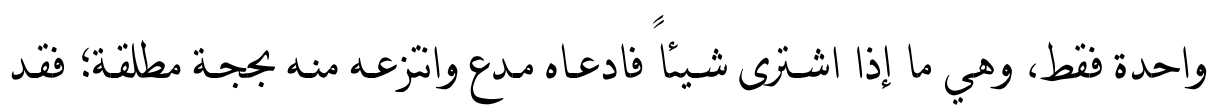
اتقق الشافعية على ثبوت الرجوع له على البائع، بل لو باع المشتري أو وهب واتزع المال من المتأهب أو المشتري منه؛ وكان لمشتري الأول الرجوع وخالف في اعتبار حجته

[الاستصحاب حجة] - إلى أن من أقسام الاستصحاب نوعاً يعرف بـ: الاستصحاب

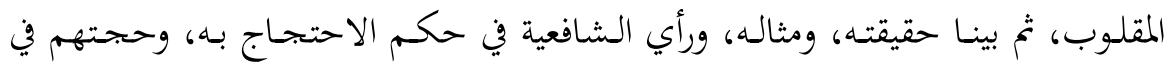
ذلك، وأشهر الفروع الفقهية التي بناها فقهاؤهم عليه.

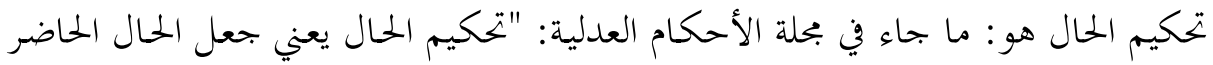

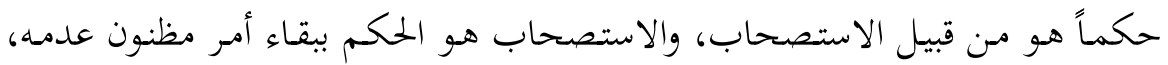
وهو بمعنى إبقاء ما كان على ما كان"

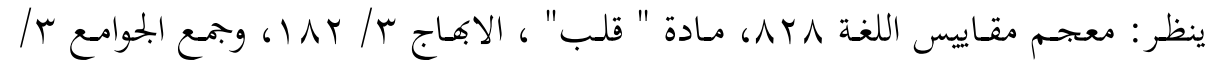

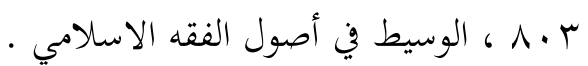


من الشافعية القاضي حسبن وآخرون، وقد ذكر بعضهم صورا آخرى للاستصحاب المقلوب وإن كانوا لم بقنقوا عليها .

الوجه الثاني: لو سلمنا بججية الاستصحاب المقلوب؛ فلا نسلم أن هذه المسألة داخلة تحته؛ لأن موضع الرمي معلوم ولكن مساحته غير محددة لا في زمن النبي لَّلي وأصحابه ولا بعدهم، ولم بحدث الجدار كما أسلفنا إلا عام بوب اهـ فلم تبتت في هـا العصر حدود ولا مساحة لكي يقال بأنها ثابته فيما سبت بالاستصحاب المقلوب، وإن وجدت هذه الحدود فمن الذي يجزم بأنها من عصر النبي لئس وأنها لم تتغير إلى الآن، والاصل في كل حادث تقديره بأقرب زمن ولا يقال بقّدمه بدون دليل. ويجُاب على هذه المناقشة بمـا ليلي: أما القول بأن الاستصحاب المقلوب ليس بججة معتبرة، فقد يقال مثل في غير هذا الموضع، ومواضع المناسك لا يرد هذا القول؛ لأن تواطؤ الجم النفير على اعتبار هذه الأحواض منذ وضعت، وعدم النكير على وضعها؛ مع توافر العلماء وكترتهم في مواسم الحج توافر دواعي الإنكار (1)، فدل ذلك على أن هـا الاجتهاد في تحديد المرمى هو الحـق إن شـاء الله، وسـواء اعتبرناه استصحابا

(1) حواشي الشرواني على التحفة ع / هـ ا. 
متلوبا، أو اعتبرناه إجماعا سكوتيا "الأمر واسع، والمقصد اعتبار هذه الأحواض؛ فإذا تبت ذلك فلادد من وجود دليل.

وأما القول بأن المسألة غير داخلة تحت الاستصحاب المقلوب؛ لأنه لم بُبت في هـذا الزمان حدود ولا مساحة لكي يقال بأنها ثابتة فيما سبق، وأن الحدود وإن وجدت فمن الذي يجزم بأنها من عصر النبي؛ وأنها لم تنغير إلى الآن.

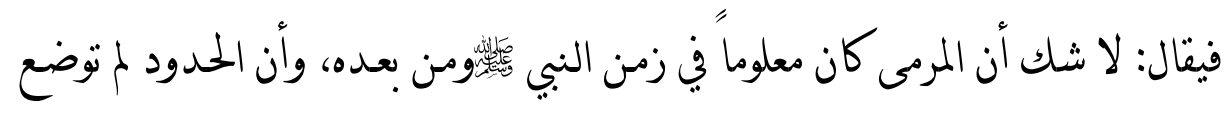
حتى وجدت الحاجة لإزالة الزحام كما أسلفنا بناء على العلم المستّر عند أهل ذلك العصر عمن كان قبلهم بـالمرمى، فوضع الحموض؛ كجديد ما اندرس من العلامات الشرعية؛ كحدود الحرم، والمشاعر ونخوها؛ فليس فيه إحداث، وإنما فيه إبضاح وإبراز لما هو مستقر ومعلوم. وجـه آخر في الجحواب: أن القول بجواز التوسعة يستلزم القول بنقص حدود المرمى في الزمن السابق، ولا يقال هذا مع وجود الجموع العظيمة المتعاقبة من العلماء التي تنكر ذلك. 
الدليل الثاني: الاستّلال بقاعدة سد الذرائع على منع بناء حوض خارجي أوسع من الحالي؛ ومعنى ذلك أن بناء هذا الحوض الخارجي يؤدي إلى التباس من المرمى على الناس؛ فيرمون فيه، والرمي فيه متمنع؛ لأن هذه القطعة ليست من المرمى، وقاعدة سـد

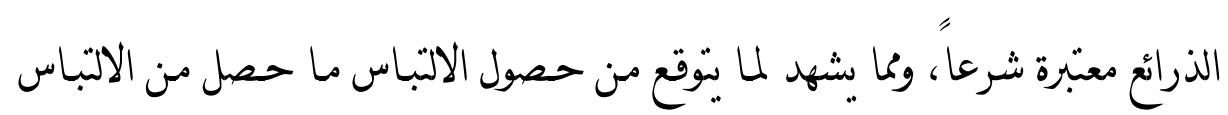
على الناس لما أزيل الجبل الواقع شرق العقبة، والذي كان متصلاً بها، حيث صار بعض الناس يرمون هذه الجمرة من الجهة الشرقية في غير المرمى. ومن أوجه منع التوسعة سدا للذرائع التلاعب في مشاعر كما قال الإمام مالك رحمه الله لمارون الرشيد لما أراد هدم ما بنى الحجاج ورد بناء ابن الزير فقال: " ناشـدنك الله با أمير المؤمنين أن بتعل هذا البيت معلبة للملوك لا شاء واحد منهم ققض البيت وبناه فتذهب هيبة البيت من

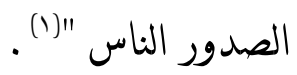

\section{ونوقش هذا الاستدلال هن وجهين}

الأول : أن تطبيق قاعدة سـد الذائع في هـذه المسألة ليس بـأولى مـن تطبيق قاعدة: المشقة بجلب التيسير، وإذا ضاق الأمر اتسع، وخوها، لا سيما مع عدم وجود دليل

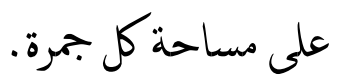

$$
\text { (1) التمهيد لابن عبد البر • / } 9 \text { ـ . }
$$


الثاني: لا نبنغي التوسع في الأخـذ بقاعدة سـ الذراعُ في الأمور الظنية؛ لأنه قد يحدث غلو في القول به ومبالغة

الدليل الثالث: أن الأصل في شحديد المشاعر التوقيف؛ فلا دخل للعقل فيها بزيادة ولا نقص أو تغير عن مواضعها، والتحديد وإن لم بكن بوضع جدار ونحوه؛ فإنه معلوم مستقر عند الناس أنه بهذا التحديد نقربِاً؛ وإلا لأنكروه واشتهر إنكارهم له، وهذا الدليل من أقوى أدلة المانعبن من توسعة أحواض الجمرات. وإذا لزم الأمر فإن إزالة

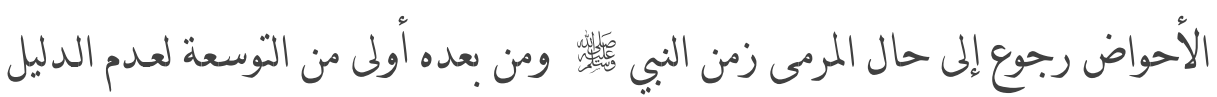

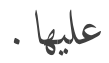

\section{استدل القائلين بقول بجماز توسعة أحواض الجمرات بها يأتي:}

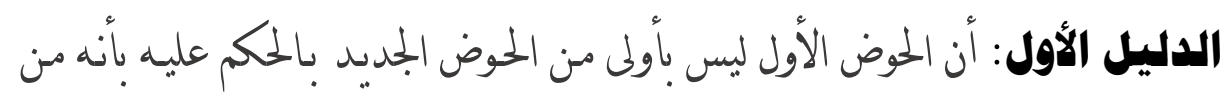

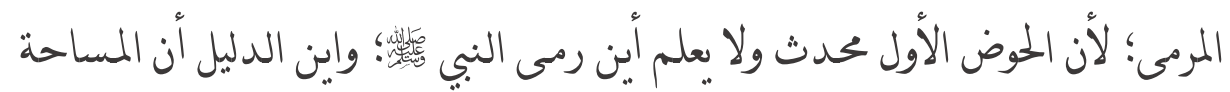
الموجودة كلها محل الرمي دليل على أن المساحة غير محدودة وإلا لما حصل الخلاف . . لم الـدليل الثـاني : أن خلاف أهل العلم في محل الرمي دليل على أن المساحة غير محدودة وإلا لما حصل الخلاف. 
الداليل الثالث: أن القول بأن الرمي إلى جتمع الحصى قول جيد؛ لأن جمع الخصى

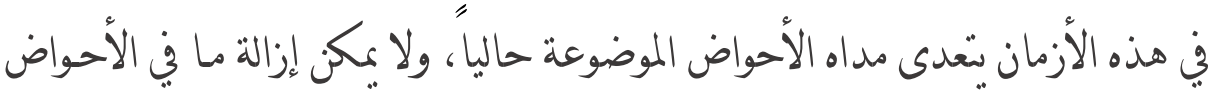

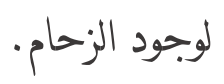

والقول بهذه المساحة المحدودة التي لايجوز بتاوزها يترتب عليه أن من رمى إلى بجمع

$$
\text { الحصى في هذه الأإم لايصح رميه. }
$$

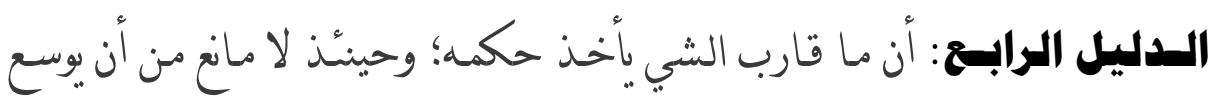

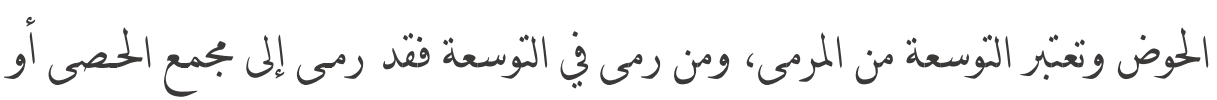
قربياً منه، وذلك مثل توسعة المسجد الحرام دخلت في حكمه بعد إلحاقها به.

الدليل الخـاهس : أن رفع الحرج عن الناس في المرمى الذي قد حصلت فيه من الوفيات ما الله به عليم؛ أولى من رفع الحرج عن الناس في المطاف في زمن عمر عندما

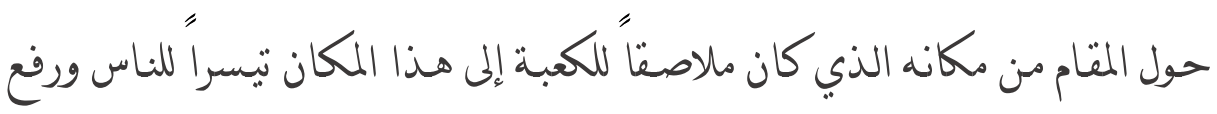
للحرج عنهم مع أنه م يحصل فيه وفيات والله أعلم. 


\section{الأدلة القائلون بجواز التوسعة فيسكن أن يجاب بإجمال:}

إن التحديد الأول مما اجتمعت عليه كلمة العلماء؛ مما يدل على اعتباره لا سيما وقد علمنا بأنه دليل واضح على بمع الحصى ، فما المانغ ين انقائه على حاله من غير

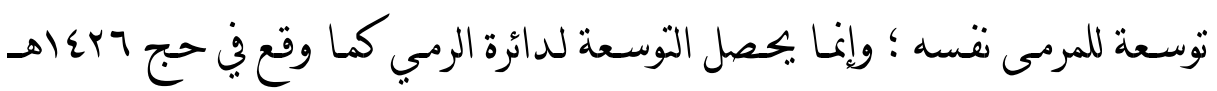
حيث زيدت دائرة الرمي من غير زيادة للمرمى، وترتب على ذلك إزالة المشقة المذكورة ورفع الحرج ، مع بقاء المرمى على حاله ، ولا شك أن هذا الغعل يعتبر من توفيق الله

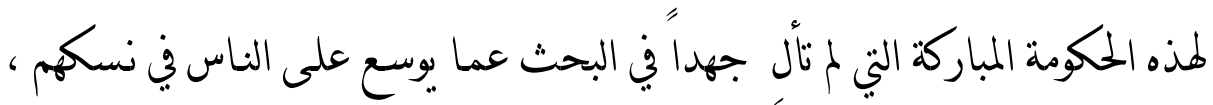

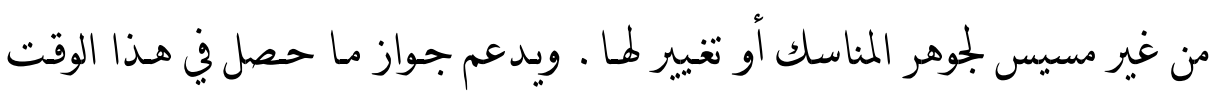

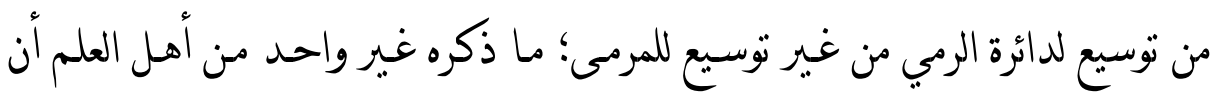
الجمار إذا وقعت دون المرمى ثم تدحرجت حتى وقعت فيه فالرمي صحيح لا غبار عليه، وهذا هو ما يكصل بعد تطبيق هذه الفكرة الممتازة.

وهن وجه آخر: فلو مخحصل هذه الفكرة الحاصلة الآن فلا بقال بمّوسعة الحوض وإنما بإزالها؛ لأن المرمى هو بجمع الحصى فإذا وقعت الجمار فيه فالرمي صحيح وإنما قلنا

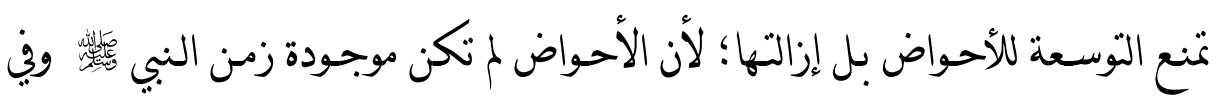




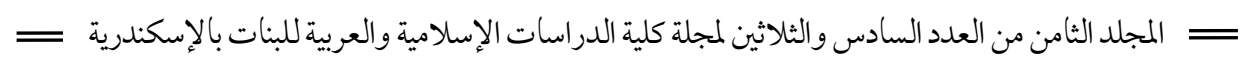

توسعة أحو اض مرمئ الجمرات ورأي الفقهاء فيه

بنائها تحديد لمكان الرمي والشارع لم بحدده، والمرجع في ذلك بجمّع الحصى وهو يزيد كرن

الحجاجه وفي زمانــا قد تضاعفوا أضعافاً مضاعفة، وهـذا من التيسير المبني على

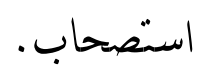

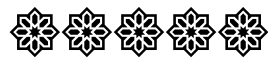




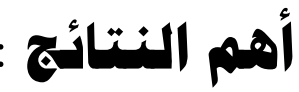

والذي يظهر والله أعلم- هو جواز نوسعة الجمرات للاعتبارات الآتية:

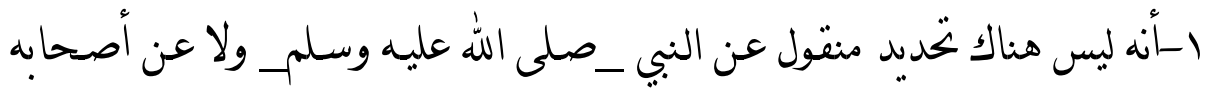

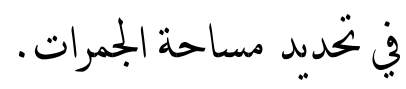

ب-أن هناك حاجة ماسـة لتوسعة الجمرات لضيق دائرة المرمى، ولما بيكصل فيها من الزحام الشديد، والحاجة تنزل منزلة الضرورة"(1) .

ب-أن في توسعة الحجرات تيسبراً ورفعاً للحرج وقد قال نعالى (وما جعل عليكم في

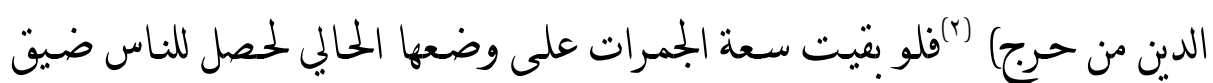
وحرج شديد لشدة الزحام الحاصل في هذا الزمان.

ع-أنه ليس هناك ما ننافي هذا القول ولا ما يدل على بطلانه فلا ينبغي المصير إلى ما فيه تشديد وتضييق على الناس وترك ما فيه توسعة ورفع للحرج والأصول تقضي متي $\cdot(r)$

$$
\begin{aligned}
& \text { (1) الاشباه والنظائر 1V9. }
\end{aligned}
$$

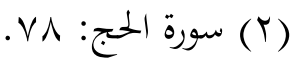

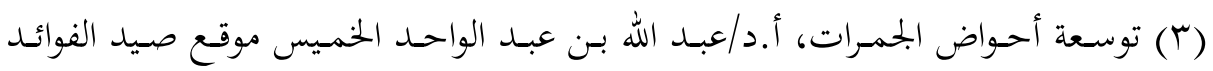

$$
\begin{aligned}
& \text { http://www.saaid.net/mktarat/hajj//rr.htm }
\end{aligned}
$$


ب ا ب أبجاث هيْة كبار العلماء بالمملكة العربية السعودية، هيُّة كبار العلماء، الرئاسة

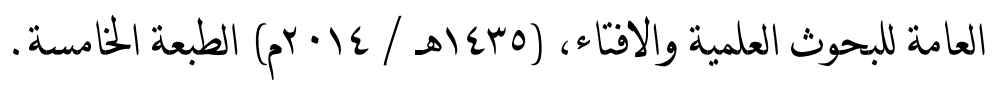

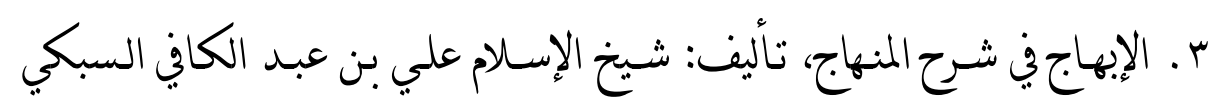

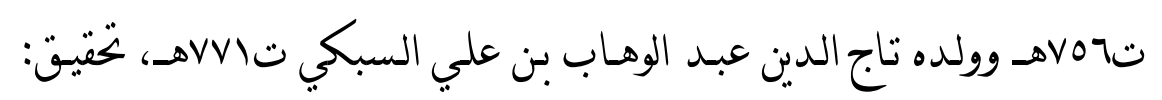

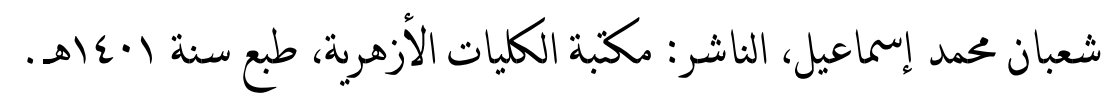

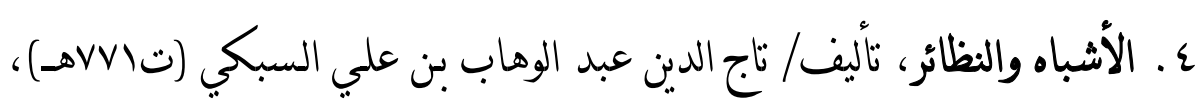
تحتيق/ عادل عبد الوجود وعلي معوض، الناشر / دار الكتب العلمية، بيروت،

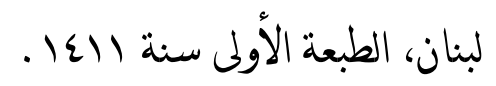

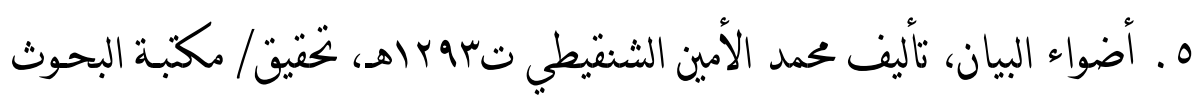
والدراسات، الناشر / دار الفكر، بيروت، لبنان سنة اعاهـ. 1. تبيين الحقائق، شرحكز الدقائق، تأليف: فخر الدين عثمان بن علي الزيلعي، الناشر/ دار الكناب الإسلامي، الطبعة الثانية. 


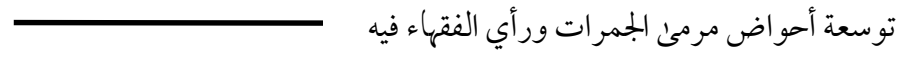

V. . تكملة المجموع شرح المهذب، ناليف: نقي الدين علي بن عبد الكافي السبكي،

ت707هـ، تحقيق: محمد بجيب المطيعي، الناشر: المكنبة العالمية بالفجالة.

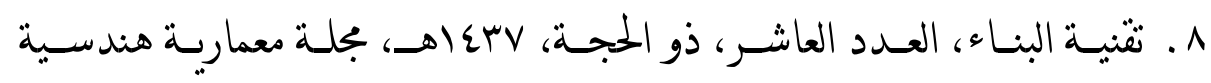

متخصعة محكمة تصدر عن الشُون القروية والبلدة.

9 ـ التمهيد لما في الموطأ من المعاني والأسانيد، تأليف: ابن عبد البر القرطبي، تحفيق: لجنة من العلماء، الناشر: وزارة الأوقاف المغربة، المغرب.

• ا . توسعة أحواض الجمرات، عبد الله الخميس،موقع صيد الفوائد .

11 ـ الاستُصحاب المتلوب (شيكيم الحال) الدكور: أحمد بن عبد الله .ن محمد

$$
\text { الضوبحي -قسم أصول الفقه -كلية الشريعة ـجامعة الإمام محمد بن سعود }
$$

Y . . جمع الجوامع، تأليف/ تاج الدين عبد الوهـاب .ن علي السبكي ت تVVهـ،

الناشر/ دار الكنب العلمية، يِروت، لبنان، الطبعة الثانية، سنة ع ععاهـ هـ

با. . حكم رمي الجمـرات من الأدوار العُلى، إعـداد: عبـد الرحمن بن فواد جـار

$$
\text { الله. إشراف أ . د ـ صالح بن عثمان بن المليل. . }
$$


عا . حاشـية ابن عابـدين (رد المتّار على الدر المختّار) تأليف/ محمد أمبن، المعروف ب: ابن عابدني ت ب ror اهـ، الناشـ/ دار الفكر، بيروت، الطبعة الثانية

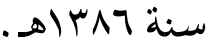

10 . حواشـي الشرواني، تأليف/ عبـد الحميـد الشرواني، الناشـر/ دار الفكر،

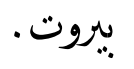

17 . . رمي الجمرات . . . تارخخ وشعائر، إعداد: أ. د. ـ. عبد الملك بن دهيش . V V . . دليل إعداد الرسائل العلمية والمشروعات البحثية عمادة الدراسـات العليا، وزارة النعليم العالي، الجامعة الاسلامية، عبع اهـ-Oبع اهـ

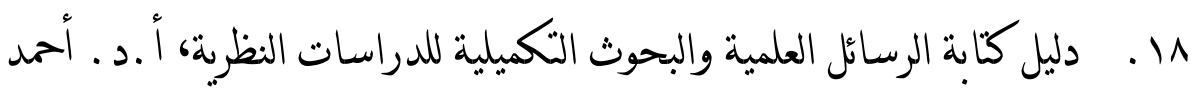

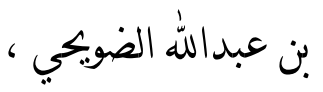
19 ـ . صحيح البخاري "الجامع الصحيح "، تاليف: محمد بن إسماعيل البخاري، الناشر: محمد علي الصبيح، بميدان الأزهر، مصر. • · . صحيح مسلم، تأليف مسلم بن الحجاج القشيري النيسابوري، تشقيق/ محمد

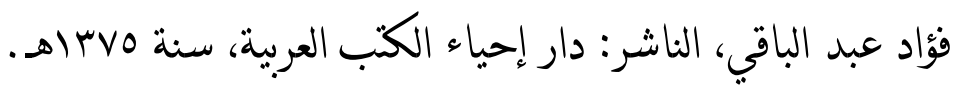


ا Y. . معجم مقايس اللغة، تأليف/ أبي الحسبن أحمد بن فارس بن زكريا ت90هـ،

الناشر/ دار إحياء التراث العربي، الطبعة الأولى، سنة r بعاهـ.

Y. . المغني، تأليف/ موفق الدين أبي محمد عبد الله بن أحمد بن قدامة القدسي

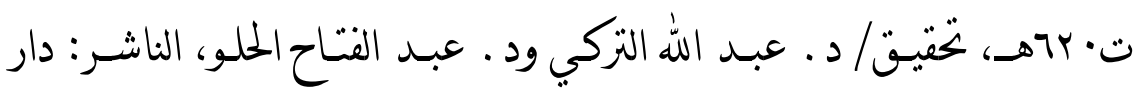

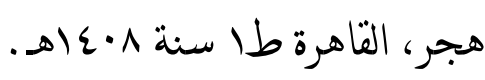

بr . مغني المحتاج، تأليف/ محمد الخطيب الشربيني، الناشر/ دار الفكر، بيروت. عَ. المصباح المنير في غريب الشرح الكبير. تأليف: أحمد بن محمد بن علي المقري

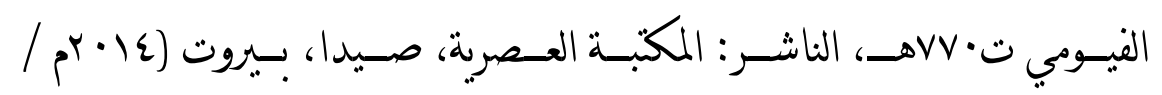

. (ه) ERO

Or. . المعتمد في أصول الفقه، تأليف: أبي الحسن محمد بن علي بن الطيب البصري

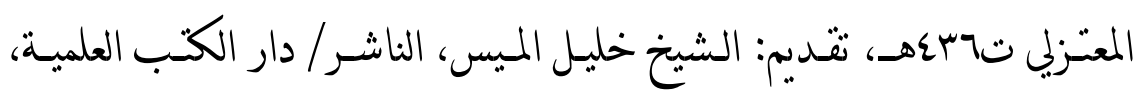

جr . النوازل في الحج، تأليف: علي بن ناصر الشلعان، دار التوحيد النشر، الرياض، الطبعة الأولى، (ابعاهـ - · ·rم) . 
rV . . الموسوعة الميسرة في فقه القضايا المعاصرة إعداد مركز التميز البحثي في فقه

$$
\text { القضا المعاصرة، الطبعة الأولى (بع اهـ/ عا• rم) }
$$

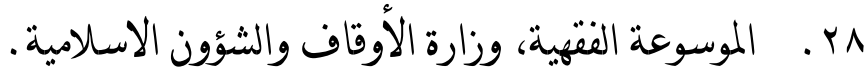

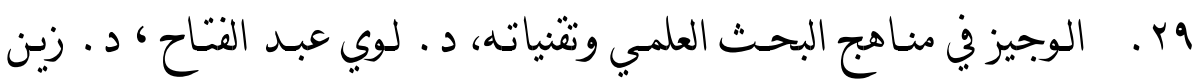

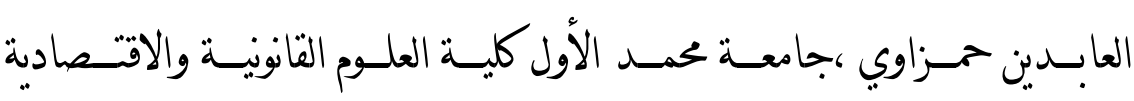

$$
\text { والاجتماعية ، وجدة - المغرب }
$$

•r. . . الوسيط في أصول الفقه الإسلامي، تأليف/ وهبه الزحيلي، الناشر/ جامعة

$$
\text { دمشق. }
$$

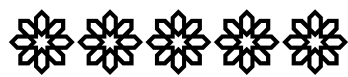

